\title{
Antenatal laparoscopic management of ovarian cyst: a case report
}

\author{
Niyaf N. A., Ravikanth G. O.*, Geeta Doppa, Bhavya H. U.
}

Department of Obstetrics and Gynaecology, KVG Medical College and Hospital, Sullia, Karnataka, India

Received: 02 January 2021

Revised: 08 February 2021

Accepted: 09 February 2021

\section{*Correspondence:}

Dr. Ravikanth G. O.,

E-mail: drravikanthgo@gmail.com

Copyright: (c) the author(s), publisher and licensee Medip Academy. This is an open-access article distributed under the terms of the Creative Commons Attribution Non-Commercial License, which permits unrestricted non-commercial use, distribution, and reproduction in any medium, provided the original work is properly cited.

\begin{abstract}
The frequency of adnexal mass in pregnancy ranges from $2 \%$ to $10 \%$, dermoid cyst is the most common ovarian germ cell tumor during pregnancy which could be asymptomatic or symptomatic, management through laparoscopy must be considered as it provides several advantages, including reduced postoperative pain, analgesic use, hospitalization time and better cosmetic result. Here we are reporting a case of an unbooked 35 years old primigravida at 16 weeks and 4 days gestation with history of retention of urine. Ultrasound showed a live foetus of 16 weeks gestation with bilateral mild maternal hydroureteronephrosis and complex cystic mass of $13 \times 10 \mathrm{~cm}$ in right lumbar region suggestive of ovarian mass. Patient was clinically stable, hence exploratory laparoscopy was taken up the next day. Intraoperatively, dermoid cyst was found in the right ovary. Right ovarian cystectomy was performed. She had an uneventful postoperative period and discharged. She was monitored for the rest of the pregnancy and it was uneventful. She had spontaneous full term normal vaginal delivery of female baby weighing $2.8 \mathrm{~kg}$. Although the patient was clinically stable, large ovarian cyst are predisposed for future complications, hence antenatal diagnosis and appropriate intervention is crucial for good outcome.
\end{abstract}

Keywords: Laparoscopy, Ovarian cyst, Pregnancy

\section{INTRODUCTION}

The incidence of ovarian cysts in pregnancy varies between studies, depending upon the study population, the inclusion criteria and the size of ovarian cysts. If a cut off of $>3 \mathrm{~cm}$ is used, the incidence in pregnancy is $1.2 \%$, if a cut off of $>5 \mathrm{~cm}$ is used the incidence in pregnancy is $0.05 \% .^{1}$

Since the introduction of routine obstetric ultrasound examination adnexal masses are diagnosed more frequently than before. The incidence of adnexal masses during pregnancy is estimated to be $0.2-2 \%$ depending on the stage of pregnancy, among which there is $1-6 \%$ of malignancy rate, the vast majority of these masses are benign. ${ }^{2,3}$ Corpus luteum cyst and benign cystic teratoma contribute two thirds of the cases.
Mature cystic teratoma is one of the most common ovarian tumors, accounting for 10-20\% of all ovarian neoplasms. It occurs in young women (20-35 years of age) in approximately $80 \%$ of the cases. ${ }^{4}$

Most pregnancy-associated cysts, such as corpus luteal and follicular cysts, resolve by gestational age 14-16 weeks and are hormonally responsive, allowing conservative management. ${ }^{5}$ By gestational age 16-20 weeks, up to $96 \%$ of masses resolve spontaneously. Resolution of cysts are less likely when larger than $5 \mathrm{~cm}$ or of complex morphology. ${ }^{6}$ Masses which are still present after 16 weeks of gestation are predominantly non-functional and simple cysts smaller than $6 \mathrm{~cm}$ in diameter have a risk of malignancy of less than $1 \%$. $^{7}$

However, for pregnant women with acute pelvic pain or an adnexal mass greater than $6 \mathrm{~cm}$ in diameter, selective 
surgical excision is not disputed. As the pregnancy progresses torsion, rupture of the cyst and other complications may occur. In all ovarian tumours in pregnancy, surgical intervention varies from 0.0004 to $0.36 \%{ }^{8,9}$

In this context, we report a case of ovarian cyst in a pregnant woman who presented with acute urinary retention and was managed laparoscopically in early pregnancy with successful outcome.

\section{CASE REPORT}

An unbooked 35 years old primigravida with 16 weeks and 4 days of gestation presented with difficulty in passing urine and distention of lower abdomen with agonising pain in suprapubic region for which she was catheterised in primary health centre and referred to us for further management. The ultrasound scan showed a live foetus of 16 weeks gestation complex cystic mass of $10.2 \times 8 \mathrm{~cm}$ in right lumbar region suggestive of ovarian mass. Patient had mild pain which was of diffuse nature, reduced in intensity after catheterisation. She had similar complaints 4 weeks back for which she was catheterised for a week. Her previous menstrual cycles were regular.

On examination her vitals were stable. Abdominal examination revealed uterine height corresponding to around 24 weeks of gestation, no tenderness and guarding but a fairly large mass, central and deviated to right side movable in all direction of $12 \times 10 \mathrm{~cm}$ was felt. She was then taken for ultrasound examination which showed a single intrauterine live pregnancy of 16-17 weeks with bilateral mild maternal hydroureteronephrosis, complex cystic mass lesion of $13 \times 10 \mathrm{~cm}$ in right lumbar region suggestive of dermoid cyst of ovary. She was started on parenteral analgesics and preliminary investigations were sent. Her pain subsided, but due to the large size of ovarian cyst and anticipating the possible complications as pregnancy progresses, she was taken for elective laparoscopic ovarian cystectomy on the next day.

Under general anaesthesia, patient was positioned in Lloyd Davies position, Foleys catheterisation was done. Primary trocar $(10 \mathrm{~mm})$ was inserted at the supraumbilical region, pneumoperitoneum was created using $\mathrm{CO}_{2}$ with a pressure of $12 \mathrm{mmHg}$ followed by insertion of three secondary trocar $(5 \mathrm{~mm})$ under vision, at the right and left lower quadrant and ipsilateral port on left side making an angle with left lower and umbilical port respectively.

A gravid uterus and ovarian cyst of $12 \times 10 \mathrm{~cm}$ on the right side was noted (Figure 1).

Cyst was punctured and pultaceous material with debris noted, dermoid cyst of the ovary was diagnosed. Cystectomy was done by separating the cyst wall and the ovarian tissue by stripping and sharp scissor dissection (Figure 2-4).

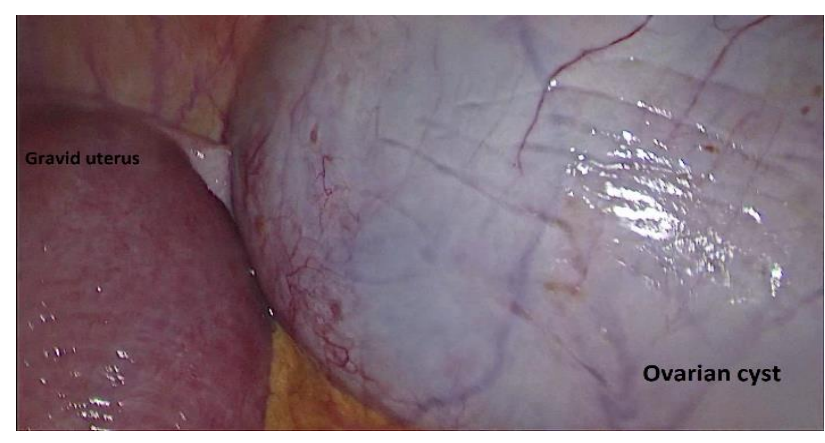

Figure 1: Laparoscopic view of gravid uterus with ovarian cyst $(12 \times 10 \mathrm{~cm})$ on right side.

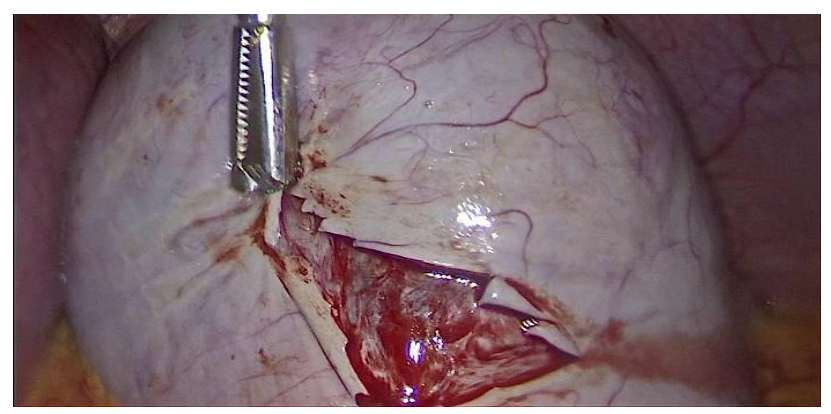

Figure 2: Cyst wall separated using toothed grasper.

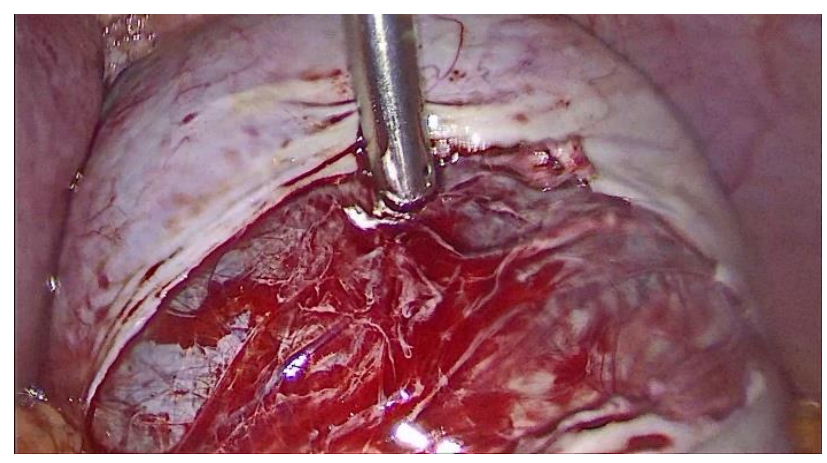

Figure 3: Cyst was punctured to decompress it.

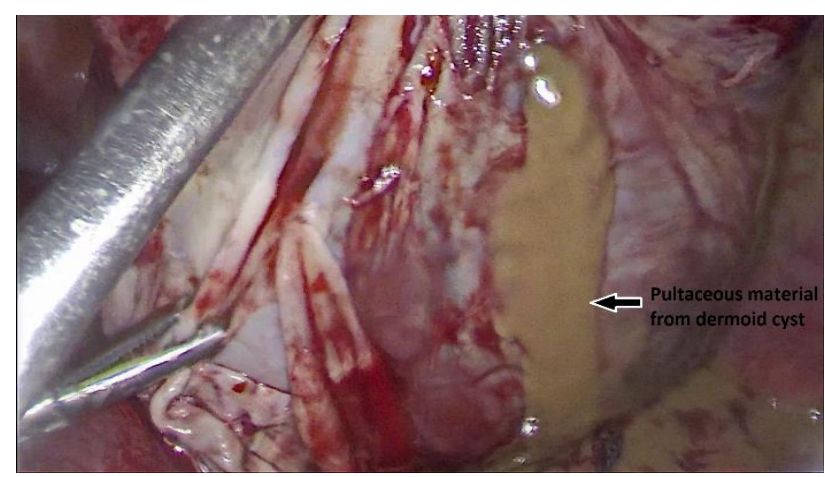

Figure 4: Pultaceous material noticed in the cyst, suction and irrigation done.

Right ovary was preserved and haemostasis achieved. Irrigation with copious amount of fluid was done to remove particles of cyst content. Other side ovary and 
fallopian tube were normal. No intraoperative complication was encountered with procedure time of 90 mins.

On gross examination, the cyst contained pultaceous material with hair.
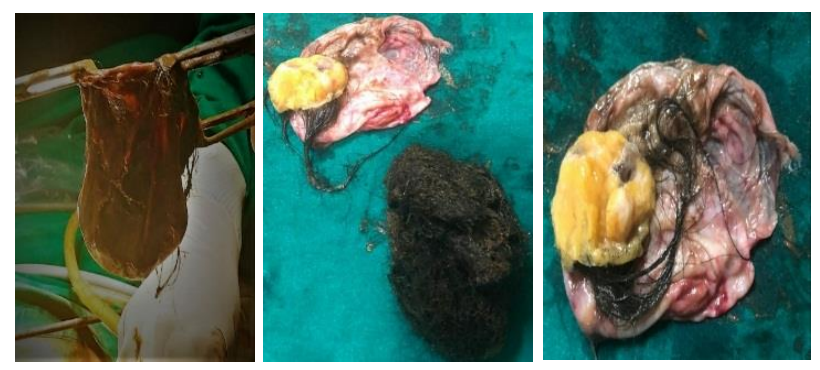

Figure 5: Cut section of specimen showing hair and pultaceous material.

Prophylactic antibiotics were administered. The fetal heart was auscultated before and after the procedure. Postoperative period was uneventful and postoperative scan revealed single live intrauterine foetus and right adnexa showed normal flow. Patient was stable and discharged on post-operative day 5. Histopathological examination (HPE) confirmed the diagnosis of dermoid cyst.

She had spontaneous full term normal vaginal delivery of female baby of $2.8 \mathrm{~kg}$, with Apgar score 7 at 1 minute and 9 at 5 minutes and was discharged on postnatal day 3 .

\section{DISCUSSION}

A typical corpus luteum cyst is $<3 \mathrm{~cm}$ in diameter and usually resolves. Ovarian cysts with diameter $\geq 6 \mathrm{~cm}$ which persist or enlarge beyond 16 weeks' gestation, are at risk of complications. 10 Complications of cysts associated with pregnancy are torsion of the cyst, rupture, infection, malignancy, impaction of cyst in pelvis causing retention of urine, obstructed labour and malpresentations of the fetus. Some studies have suggested surgical intervention for concerns of malignancy, tumor torsion, tumor rupture, or obstruction of labor. ${ }^{11,12}$ Other studies have recommended the principle of observation, finding that most ovarian masses can either remain uneventful or resolve throughout pregnancy and that the incidence of the above risks was actually low. ${ }^{11,13}$ Mature cystic teratomas grow slowly at an average rate of $1.8 \mathrm{~mm}$ each year, prompting some investigators to advocate nonsurgical management of smaller $(<6 \mathrm{~cm})$ tumors. ${ }^{14}$

Mature cystic teratomas requiring removal can be treated with simple cystectomy. The tumors are bilateral in about $10 \%$ of cases. In our case patient presented with second episode of acute retention of urine which had to be managed surgically as further complications may necessitate emergency surgery which carries a higher risk of foetal wastage compared with elective surgery.
Furthermore, the risk of obstruction of labour is calculated to be $17 \%$ to $21 \%$. $^{15}$

Once the surgical management decision is taken, the choice of approach is the next consideration. We chose to manage the case laparoscopically. There is evidence to suggest that laparoscopy and laparotomy do not differ with regard to foetal outcome, that is, foetal weight, gestational age, growth restriction, infant survival and foetal malformations. ${ }^{15}$

Since the mid-1990s, laparoscopy has been widely used in nonpregnant women's gynaecologic diseases. Nowadays, a growing number of evidences show that laparoscopy can be safely and effectively used during pregnancy, and provides several advantages, including reduced postoperative pain, analgesic use and hospitalization time. However, the major advantages of laparoscopy are magnification and panoramic view of the pelvis resulting in reduced intraoperative uterine manipulation which may lead to decreased postoperative uterine irritability, miscarriage rate and preterm labour which is seen in $50 \%$ of third trimester cases with an open approach. There are several reports on the safety of the laparoscopic procedure for gynaecologic and non-gynaecologic surgery such as cholecystectomy and appendicectomy during the second trimester of pregnancy with no increase in miscarriage rate. ${ }^{16}$ In addition, the cosmetic results are much better and the discomfort of stretching and distension of the laparotomy scar due to the rapidly growing uterus is avoided. Bearing in mind that uterine surface in pregnancy is more friable and can bleed more easily on contact even with blunt instruments, a 'no touch' approach should be adopted.

However, we must be cautious of the possible risk of laparoscopy. The risk of fetal loss has become the top priority in many studies of the relative safety of laparoscopy in pregnancy. The main consideration is laparoscopy requires carbon dioxide pneumoperitoneum. Increased intraabdominal pressure can lead to reduced uterine blood flow and maternal venous return, resulting in the fetal intrauterine hypoxia. Another factor associated with pneumoperitoneum is that carbon dioxide can be absorbed across the peritoneum, causing fetal acidosis. ${ }^{17}$ However, Curet et al states that there is no substantial adverse effect on the fetus when the maximum pressure of the pneumoperitoneal is less than $12 \mathrm{mmHg}$ and the duration is less than 30 min. ${ }^{18}$ For operative laparoscopy, adequate exposure is possible with low pressure, although a short period of higher pressure increases the safety of port insertion. To avoid this risk, the gasless laparoscopic technique was, therefore, recommended for pregnancy surgery. ${ }^{19}$

In laparoscopic surgery during pregnancy, the risk is the injury to the enlarged uterus. The location of the primary port will depend on the level of the uterine fundus. The uterine size should be determined by palpation or ultrasound. In the study of Balthazar, initial port was 
placed through an open method $(80 \%)$ or a left upper quadrant entry $(11 \%)$, thereby reducing the potential risk of penetrating injury to the gravid uterus. ${ }^{20}$ The laparoscopic entry technique is less of a concern in the first trimester because the pregnant uterus remains in the pelvic cavity and as the gestational age increases, one must be more vigilant. Clinicians should be aware that in experienced hands direct (gasless) entry may be an alternative, but there is insufficient information in late pregnancy to suggest this as a routine approach. Chen et al reported direct entry in 33 laparoscopies for ovarian cysts in second trimester (mean gestation 16.8) without entryrelated complications. ${ }^{21}$ Secondary port placements will be dictated by uterine size, pathology and operative approach. Given the limited degrees of freedom in laparoscopic surgery and the added obstacle of the size of the pregnant uterus, ipsilateral port placement may circumvent this obstacle. Due to restricted access and visibility the surgeon needs to respect electrosurgical principles to avoid trauma. General safety rules for monopolar diathermy are applicable: avoiding indirect thermal damage, pedicle effect, avoid coupling, checking for faulty insulation.

Large cystic masses may require decompression to fit though a small incision. By decompressing a cyst into a laparoscopic bag, spillage can be minimal or non-existent. If no, the copious irrigation also helps to keep the residual content to a minimum. After cystectomy, the ovarian incision can be left open or approximated by three techniques: fine monofilament suture of the edges, tissue glue or coagulation of the ovarian cortex adjacent to the surface.

\section{CONCLUSION}

Laparoscopic surgery in pregnant women with adnexal mass is associated with less operative blood loss, reduced time in hospital stay and decreased rate of preterm labour. Hence timely intervention by a surgeon with advanced laparoscopic skills can prevent future complications related to cyst in pregnancy.

\section{Funding: No funding sources}

Conflict of interest: None declared

Ethical approval: Not required

\section{REFERENCES}

1. Duic Z, Kukura V, Ciglar S, Podobnik M, Podgajski M. Adnexal masses in pregnancy: a review of eight cases undergoing surgical management. Eur J Gynaecol Oncol. 2002;23(2):133-4.

2. Hoover K, Jenkins TR. Evaluation and management of adnexal mass in pregnancy. Am J Obstet Gynecol. 2011;205(2):97-102.

3. Runowicz CD, Brewer M. Adnexal mass in pregnancy. Available at: https://www.uptodate .com/contents/adnexal-mass-in-pregnancy. Assessed on: 21 August 2020.
4. Jamor J, Conte AB, Alaoui FZF, Jayi S, Chaara H, Melhouf MA. Malignant transformation of ovarian mature teratoma: 04 cases report, review of the literature. Int J Reprod Contracept Obstet Gynecol. 2020;9:819-24.

5. Glanc P, Salem S, Farine D. Adnexal masses in the pregnant patient: a diagnostic and management challenge. Ultrasound Q. 2008;24(4):225-40.

6. Giuntoli RL, Vang RS, Bristow RE. Evaluation and management of adnexal masses during pregnancy. Clin Obstet Gynecol. 2006;49(3):492-505.

7. American College of Obstetricians and Gynecologists' Committee on Practice Bulletins Gynecology. Practice Bulletin No. 174: Evaluation and Management of Adnexal Masses. Obstet Gynecol. 2016;128(5):210-26.

8. Sherard GB, Hodson CA, Williams HJ, Semer DA, Hadi HA, Tait DL. Adnexal masses and pregnancy: a 12-year experience. Am J Obstet Gynecol. 2003;189(2):358-63.

9. Bunyavejchevin S, Phupong V. Laparoscopic surgery for presumed benign ovarian tumor during pregnancy. Cochrane Database of Systematic Reviews. 2013;1:CD005459.

10. Al-Fozan H, Tulandi T. Safety and risks of laparoscopy in pregnancy. Curr Opin Obstet Gynecol. 2002;14(4):375-9.

11. Yen CF, Lin SL, Murk W, Wang CJ, Lee CL, Soong YK, et al. Risk analysis of torsion and malignancy for adnexal mases during pregnancy. Fertil Steril. 2009;91(5):1895-902.

12. Whitecar MP, Turner S, Higby MK. Adnexal masses in pregnancy: a review of 130 cases undergoing surgical management. Am J Obstet Gynecol. 1999;181(1):19-24.

13. Schmeler KM, Mayo-smith WW, Peipert JF, Weitzen S, Manuel MD, Gordinier ME: Adnexal masses in pregnancy: surgery compared with observation. Obstet Gynecol. 2005;105(5):1098-103.

14. Caspi B, Appelman Z, Rabinerson D, Zalel Y, Tulandi T, Shoham Z. The growth pattern of ovarian dermoid cysts: a prospective study in premenopausal and postmenopausal women. Fertil Steril. 1997;68(3):501-5.

15. Sanaullah, F., Trehan, A.K. Ovarian cyst impacted in the pouch of Douglas at 20 weeks' gestation managed by laparoscopic ovarian cystectomy: a case report. J Med Case Rep. 2009;3:7257.

16. Neiswender LL, Toub DB. Laparoscopic excision of pelvic masses during pregnancy. J Am Assoc Gynecol Laparosc. 1997;4(2):269-72.

17. Soper NJ, Hunter JG, Petrie RH. Laparoscopic cholecystectomy during pregnancy. Surg Endosc. 1992;6:115-7.

18. Curet MJ, Vogt DA, Schob O, Qualls C, Izquierdo LA, Zucker KA. Effects of $\mathrm{CO} 2$ pneumoperitoneum in pregnant ewes. J Surg Res. 1996;63(1):339-44.

19. Sesti F, Pietropolli A, Sesti FF, Piccione E. Gasless laparoscopic surgery during pregnancy: evaluation of 
its role and usefulness. Eur J Obstet Gynecol Reprod Biol. 2013;170:8-12.

20. Balthazar U, Steiner AZ, Boggess JF, Gehrig PA. Management of a persistent adnexal mass in pregnancy: what is the ideal surgical approach? J Minim Invasive Gynecol. 2011;18(6):720-5.

21. Chen L, Ding J, Hua K. Comparative analysis of laparoscopy versus laparotomy in the management of ovarian cyst during pregnancy. J Obstet Gynaecol Res. 2014;40(3):763-9.

Cite this article as: Niyaf NA, Ravikanth GO, Doppa G, Bhavya HU. Antenatal laparoscopic management of ovarian cyst: a case report. Int J Reprod Contracept Obstet Gynecol 2021;10:1734-8. 